\title{
La relevancia de la perspectiva territorial y femenina en la construcción de paz en Colombia
}

\author{
The Relevance of the Territorial and Female \\ Perspective in the Peace Building in Colombia
}

\author{
Paris A. Cabello-Tijerina (D) https://orcid.org/0000-0002-0191-2488 \\ Universidad Autónoma de Nuevo León, México, paris.cabellotjr@uanl.edu.mx \\ Karen Quiñones (D) https://orcid.org/0000-0002-7963-8175 \\ Universidad Autónoma de Nuevo León, México, karenandreaqd@gmail.com
}

Recepción:

$25 / 04 / 2018$

Aprobación:

$23 / 11 / 2018$

\begin{abstract}
The peace process in Colombia, which puts an end to the longest internal conflict in Latin America, is a complex and multi-faceted process. The objective of this paper is to analyze Transitional Justice from the perspective of Irenology with a gender perspective. For this reason, a qualitative tool was developed consisting of a semi-structured in-depth interview in which it was observed that peace has ceased to be a matter for States and has become a matter for citizens, even though women's contributions to peacebuilding in the country are scarce. Thus, the advances achieved through the theorization of peace must be materialized in reality in such a way that the construction of peace as a process that concerns all citizens involves women not only in the political sphere but also in their daily lives.
\end{abstract}

Key words: territorial peace, transitional justice, irenology, women, Colombia.

Resumen: El proceso de paz en Colombia que pone fin al conflicto interno más largo en América Latina es un proceso complejo y con distintas vertientes. El objetivo del presente trabajo es analizar la justicia transicional desde la perspectiva de la irenología con un enfoque de género. Por ello, se desarrolló un instrumento cualitativo que consiste en una entrevista a profundidad semiestructurada, mediante la cual se observó que la paz ha dejado de ser un asunto de Estados para convertirse en un asunto de ciudadanos, aunque los aportes de las mujeres para la construcción de paz en el país son escasos. Así, se requiere que los avances logrados a través de la teorización de la paz se materialicen en la realidad, de tal manera que la construcción de la paz como proceso que concierne a todos los ciudadanos involucre a las mujeres no solo desde la esfera política sino desde su cotidianidad.

Palabras clave: paz territorial, justicia transicional, irenología, mujeres, Colombia. 


\section{Introducción}

En la actualidad, Colombia, al igual que en su momento ocurrió con otros países en América Latina, se encuentra afrontando los complejos desafíos que supone e impone el posconflicto. Este paso en dirección al logro de una paz estable y duradera en el país tiene esencialmente como fundamento el Acuerdo de Paz que ha celebrado el Gobierno Nacional con el grupo armado ilegal más poderoso de la historia colombiana y uno de los más antiguos del mundo: las Fuerza Armadas Revolucionarias de Colombia (FARC).

Como parte de las estrategias para lograr los propósitos de la transición y teniendo en cuenta el contexto del conflicto que se pretende transformar, el Acuerdo de Paz le ha apostado a un concepto de paz territorial. Este sugiere una idea descentralizada de la construcción de la paz, a fin de otorgarle un mayor grado de participación a las regiones que componen el país en los aspectos sociales, económicos y culturales que son de su interés, con especial atención en las diferencias que a raíz de estos surgen de una región a otra, pero también atendiendo a criterios de priorización que agilicen atender a la población vulnerable y a las víctimas directas del conflicto armado interno. En esa misma línea, el acuerdo exalta la importancia que tiene la protección de los derechos fundamentales de las mujeres (Gobierno Nacional y FARC, 2016: 3), con lo cual se evidencia la consideración que se ha realizado frente a ellas, en razón de las históricas condiciones de vulnerabilidad y discriminación que han padecido y las han dejado en situación de desigualdad frente a los derechos del hombre.

De acuerdo con ello y también teniendo en cuenta que en la negociación con las FARC hubo una mínima participación de población femenina, dado que los siete acuerdos fueron oficialmente signados por 43 hombres y 8 mujeres (Chaparro y Martínez, 2016: 70), resulta de trascendencia introducir el enfoque de género en este estudio para dimensionar, de manera local, cuál es la perspectiva de las mujeres respecto de lo que consideran como esas mejores formas de construir una paz estable y duradera desde su territorio y para su territorio.

El concepto de paz territorial no solo se acomoda con las realidades del conflicto colombiano, sino que, desde un punto de vista teórico, responde a las actuales tendencias marcadas por el desarrollo del campo de la justicia transicional y de la irenología, que han enriquecido tanto la forma en que actualmente se entiende esa - a veces ambigua- noción de paz, como la mejor manera de acercarse a su construcción, bien desde la óptica del respeto y garantía de los derechos humanos como desde lo que cada individuo puede 
aportar en esa dirección y sobre todo las mujeres para lo que concierne a este estudio.

Desde ese panorama, este documento comienza por contextualizar el surgimiento y concepto de la justicia transicional, como modelo que ha nacido en circunstancias que reclaman el restablecimiento urgente de la situación sistemática de violaciones de los derechos humanos y herramienta que ha permitido a muchas sociedades dar los pasos requeridos de la guerra hacia la paz, pasando luego a establecer la relación que este campo mantiene con los derechos humanos. En un primer momento, se analizará lo correspondiente a la protección privilegiada que tuvieron los derechos civiles y políticos, para, después, determinar cómo sus avances han logrado integrar y hacer extensiva esa protección a los derechos económicos, sociales y culturales.

En seguida se planteará el diálogo actual que el campo de la justicia transicional empieza a tener con la irenología como ciencia creciente encargada de los estudios de la paz. Al final y bajo este marco de estudio, se examinará el concepto de paz territorial, como estrategia incorporada de manera transversal en el Acuerdo de Paz que está siendo objeto de implementación en Colombia, teniendo en cuenta la actitud, percepción y compromiso para alcanzar una paz estable y duradera de un segmento de la población altamente vulnerable que conforma el país, como son las mujeres que no gozan de condiciones socioeconómicas favorables.

\section{Metodología}

A fin de comprender la percepción de las mujeres en situaciones de vulnerabilidad económica sobre la construcción de paz en el país en la etapa del posconflicto, se realizó un estudio cualitativo con un enfoque de género. La información se obtuvo a partir de entrevistas a profundidad semiestructuradas a mujeres mayores de edad, habitantes del barrio La Orlidia, de la Comuna 2, del municipio de Palmira, cuyos inmuebles de habitación están ubicados según la escala de estratificación socioeconómica, donde 1 es bajobajo y 6 es alto, en los estratos 1 y $2 .{ }^{1}$ Esto apunta a entender cómo dimensionan las mujeres, en estas especiales condiciones socioeconómicas, la idea de la paz en Colombia desde su cotidianidad y cuáles son sus actuales y potenciales aportes a la construcción de la misma.

1 Estratos y metodología. Los inmuebles residenciales a los cuales se provean servicios públicos se clasificarán máximo en seis estratos socioeconómicos: 1) bajo-bajo, 2) bajo, 3) medio-bajo, 4) medio, 5) medio alto, y 6) alto (Régimen Servicios Públicos Domiciliarios, 1994). 
Cada entrevista se centró en preguntas derivadas de las siguientes categorías de estudio: visión del conflicto, causas del conflicto, consecuencias del conflicto, significado de la paz, construcción de paz, encargados de la paz. Cada categoría descansa en la idea de cómo se construye la paz desde la cotidianidad de las mujeres.

Las entrevistas iniciaron con preguntas enfocadas a conseguir los objetivos de la investigación, pero también fueron diseñadas con la intención de generar un espacio de comodidad para las entrevistadas, donde pudieran manifestar sus opiniones. La información recabada se analizó con el software Nvivo para investigaciones cualitativas y mixtas, el cual está diseñado para organizar, analizar y encontrar perspectivas en datos no estructurados.

\section{Origen de la justicia transicional}

Los sistemas de justicia transicional son actualmente herramientas especiales de aplicación de justicia en escenarios de conflicto armado. Su origen bien podría ubicarse a partir del final de la Primera Guerra Mundial, aunque reflejaron mayor importancia, con características de extraordinarias e internacionales, luego de terminar la Segunda Guerra Mundial con los juicios de Nüremberg, que incluso sirvieron de base para establecer buena parte de los derechos humanos modernos, aunque en particular fueron utilizados para definir unos estándares de guerra injusta -Derecho de la Guerra- y la posibilidad de imponer castigos por conducto de la comunidad internacional.

Después, con el surgimiento de la Guerra Fría, permanecieron en estado de relativo letargo, que vino a resurgir con la finalización del tránsito hacia la democracia de los antiguos Estados del bloque comunista en 1989 y que en la actualidad, en diversos escenarios de conflicto, tienen constante aplicación como válido y efectivo ensayo de adaptación de los Estados a las reglas de los derechos humanos universales y del derecho internacional humanitario, mediante la suscripción de distintos tratados y convenios o la creación de mecanismos internacionales de justicia, de conformidad con el desarrollo de nuevas constituciones locales (Teitel, 2003).

En cuanto a su concepto, la ONU (2004) ha señalado que la justicia transicional se corresponde con:

La variedad de procesos y mecanismos asociados con los intentos de una sociedad para resolver los problemas derivados de un pasado de abusos a gran escala, a fin de que los responsables rindan cuentas de sus actos, servir a la justicia y lograr la reconciliación. Tales mecanismos pueden ser judiciales o extrajudiciales y tener distintos niveles de participación internacional -o carecer por completo de ella-, así como abarcar el 
enjuiciamiento de personas, el resarcimiento, la búsqueda de la verdad, la reforma institucional, la investigación de antecedentes, la remoción del cargo o combinaciones de todos ellos (ONU, 2004: 6).

De acuerdo con esto, a todas esas medidas, programas, acuerdos, normas y, en general, el conjunto de acciones llevadas a cabo en una sociedad para superar situaciones de extrema violencia y transitar hacia la paz se les denomina justicia transicional.

La justicia transicional ha logrado consolidarse como una manera eficaz para facilitar a las sociedades flageladas por la violencia sistemática el tránsito hacia la paz. Su fortalecimiento se debió en gran medida a los esfuerzos que se gestaron al interior de la ONU por la lucha contra la impunidad, en la cual se pasó de tener un inicial interés meramente concentrado en el tratamiento de los victimarios causantes de las atrocidades, hacia una mirada un poco más amplia que ahora sí tuviere en consideración a las víctimas. Esta visión empezó a calar y preponderar ante las necesidades de justicia de estas, quienes, pese a sufrir directamente el daño originado por una conducta delictiva, no eran tomadas en cuenta dentro de la dinámica que encerraba la comisión de un hecho punible.

Incluso, históricamente, y dentro de los contextos de los procesos de paz en el mundo, muchas veces la sola existencia de estas y sobre todo su reparación eran vistas más bien como un obstáculo para la reconciliación, ya que atender aspectos semejantes implicaba en ocasiones la sanción de los responsables de su victimización (Barbosa, 2017: 150), significando así que la impunidad resultase ser hasta la mejor aliada para la construcción de la paz.

En esas circunstancias se crearon lo que hoy se conocen como principios de lucha contra la impunidad, o principios Joinet, así llamados por el diseño propuesto por Luis Joinet, Relator Especial de la ONU, a quien la Comisión de Derechos Humanos le encargó esa tarea (Comisión Colombiana de Juristas, 2007: 71).

Estos tienen su génesis, según lo explica Joinet en su informe, como producto de la toma de conciencia de la opinión pública respecto del tema de la impunidad originada por unos puntuales hechos históricos, los cuales identifica en cuatro etapas: 1) en el decenio de 1970, cuando organizaciones no gubernamentales, defensores de derechos humanos y la oposición democrática en ciertos países, en especial en América Latina durante los regímenes dictatoriales, se movilizaron a favor de la amnistía de presos políticos; 2) en el decenio de 1980, con la proliferación de leyes de autoamnistía, que provocaron la reacción de las víctimas para exigir justicia; 3) el aumento de procesos de democratización y las negociaciones de paz para terminar con conflictos 
armados internos tras el término de la Guerra Fría, que pusieron en el centro del debate el tema de la impunidad; por un lado, el olvido que impulsaba el antiguo opresor, y por el otro, la justicia reclamada por la víctima; y 4) la preocupación e interés de la comunidad internacional sobre la importancia de la lucha contra la impunidad, en la cual se resalta la labor de la Corte Interamericana de Derechos Humanos y las declaraciones que surgieron de la Conferencia Mundial de Derechos Humanos de junio 1993 y que se concretaron en la Declaración y Programa de Acción de Viena (ONU, 1993: 30).

El tema de la lucha contra la impunidad fue puesto entonces en la agenda internacional como una respuesta a los clamores de justicia de las víctimas de los abusos cometidos sobre todo en América Latina durante los años ochenta, a causa de los regímenes dictatoriales en ese decenio.

Más tarde, ese conjunto de principios creados para hacerle frente a la impunidad se conoció como una tipología de derechos para proteger a las víctimas de graves violaciones a los derechos humanos y al derecho internacional humanitario, y que buscan satisfacer sus derechos a la verdad, a la justicia, a la reparación y a las garantías de no repetición.

De ese modo, se podría entender que la justicia transicional responde a una dinámica bidimensional: por un lado comporta la protección de las víctimas de abusos a gran escala, y por otro, el enjuiciamiento de los responsables de la comisión de estos, correspondiendo a la misma dinámica de los sistemas penales tradicionales. Esto explica que la mayoría de los análisis sobre la justicia transicional se hayan concentrado en las tensiones que emergen de una sociedad en conflicto entre justicia y paz, las cuales giran alrededor de qué tanta justicia retributiva se debe sacrificar a favor del anhelado logro de la paz.

Sin embargo, para transitar hacia una paz estable y duradera se requiere de un enfoque más extenso de la justicia transicional, como aquel que ha surgido al compararse este campo con la garantía y protección de los derechos humanos, los cuales, naturalmente, están inspirados en la construcción de sociedades pacíficas.

\section{Los derechos humanos y la justicia transicional}

Retomando los principios de Joinet (Comisión Colombiana de Juristas, 2007) antes mencionados, de manera general se les ha valorado como garantías para proteger los derechos humanos de las víctimas. Sobre este aspecto, es bueno precisar que la labor encargada de forma definitiva al relator Luis Joinet -cuyo informe final sirvió de fundamento para crear el documento 
con el conjunto de principios actualizado para la protección y la promoción de los derechos humanos, mediante la lucha contra la impunidad- se contrajo exclusivamente al estudio de la impunidad de los autores de violaciones de derechos civiles y políticos, dejando que la temática de los derechos económicos, sociales y culturales (DESC) estuviese a cargo del relator especial El Hadji Guissé (Comisión Colombiana de Juristas, 2007: 73). El informe final de este fue presentado en el $49^{\circ}$ periodo de sesiones de la Subcomisión de Prevención de Discriminaciones y Protección de las Minorías de la ONU, sin que a la postre se hubiese hecho mención alguna de ese insumo en el último documento, donde definitivamente se acogieron los principios de lucha contra la impunidad. Sin embargo, quedaron solo en la garantía y protección de los derechos civiles y políticos, dejando al margen los DESC, como se concluye de la lectura de su epígrafe.

Todo indica que el creciente campo de la justicia transicional no ha sido ajeno a la división histórica que han sufrido los derechos civiles y políticos, con los DESC, que estuvo marcada durante el periodo de la Guerra Fría y cuyas consecuencias se vivencian hoy en los modelos transicionales.

Históricamente, la justicia transicional ha estado más asociada con brindar la necesaria protección a las víctimas de graves violaciones de derechos civiles y políticos, que a las que han tenido una transgresión de sus DESC. En ese orden de ideas, cuando se hace referencia a las graves violaciones de derechos humanos, se alude en esencial, como lo indica Boven (Comisión Colombiana de Juristas, 2007: 236), a conductas relacionadas con:

El asesinato, la tortura, el establecimiento o mantenimiento de personas en estado de esclavitud, servidumbre o trabajo forzoso; la persecución por motivos sociales, políticos, raciales, religiosos o culturales de una manera sistemática o masiva; la deportación o el traslado forzoso de poblaciones.

En cuanto al núcleo de los derechos que se vulneran con las conductas descritas, estos se relacionan con el derecho "a la vida, a la integridad personal o a la libertad personal” (Boven, 1993: 66).

Sin embargo, en la realidad, ese tipo de distinciones entre derechos humanos civiles y políticos en relación con los económicos, sociales y culturales no tiene justificación, ya que -cual se enseña y afianza con la cotidianidad de las sociedades como la colombiana que ha sufrido un conflicto armado interno que supera el medio siglo- es precisamente el principio de indivisibilidad el que inspira los derechos humanos, el cual debe primar en la medida en que las violaciones sistemáticas de estos a lo largo de tantas décadas han sido pluriofensivas, de donde surge certeramente que no caben tan limitados criterios de clasificación. 
Como respaldo a esta afirmación, de acuerdo con algunas de las entrevistadas, los obstáculos para que en el país se logre una paz estable y duradera se presentan preponderantemente por situaciones que vulneran el núcleo de los derechos económicos y sociales, lo cual se refleja en lo que manifestaron:

La falta de que el gobierno se ponga la mano en el corazón y que el crecimiento económico no es para unos pocos, sino que es para la mayoría. ¿Ya? Entonces la desigualdad es mucha, el gobierno roba de una manera horrible (E4).

En ese mismo sentido, una de las informantes también señaló:

O sea, la desigualdad, porque por lo menos yo, uno de pobre dice, no, yo fuera presidente pensaba en las personas pobres, ayudaba a los pobres para que ellos tuvieran y fueran como los demás. Entonces esa es la igualdad (E17).

Por eso mismo, han sido las experiencias de las sociedades que han soportado el flagelo de esta clase de violaciones las que poco a poco fueron develando la necesidad de retomar las olvidadas iniciativas, que en principio habían resultado de interés en el seno de la ONU, pero que luego terminaron relegadas, sin mayor explicación sobre la protección para las víctimas en cuanto a sus DESC. Y con más razón, cuando las conductas que afectan el núcleo de estos derechos están directamente asociadas con las causas profundas y estructurales de los conflictos, en las cuales los problemas de la distribución equitativa de la riqueza y la atención del Estado a sus ciudadanos se minimizaron a un segundo plano, a pesar de que se trata de aspectos determinantes que no permiten la superación del conflicto (véase Gráfica $1^{2}$ ).

Una vez que se advirtieron estas circunstancias, la ONU (2014: 5), en un trabajo donde se analiza la capacidad de los Estados que usan la justicia transicional, llamó la atención por la deficiencia encontrada para atender las violaciones de este tipo de derechos, misma que ya había sido señalada por la Alta Comisionada de la Oficina de las Naciones Unidas para los Derechos Humanos, Louise Arbour, quien criticó que a la justicia transicional se le hubiere dado un enfoque que corresponde solamente a lo que ha sido la tradicional justicia criminal y, sin embargo, al mismo tiempo se dejara de lado la inclusión de los DESC, afectando el principio de indivisibilidad y la visión integral que es connatural con los derechos humanos (Arbour, 2006: 3).

A partir de estos análisis se ha venido fortaleciendo esta posición en defensa de la atención que la justicia transicional debe dar a los temas asociados con los DESC y que permite que las discusiones se concentren no solo en eliminar la violencia directa -que supone el cese de las hostilidades propias de los conflictos armados-, sino también se desplacen hacia los asuntos de

2 Todas las gráficas se encuentran en el Anexo, a final del artículo. 
justicia social; y, desde esa perspectiva, se apunte por igual a eliminar la violencia estructural, como se explicará más adelante.

En ese sentido, Sharp (2012: 811), partiendo de la construcción de paz como objetivo de la justicia transicional y tomando los conceptos de paz negativa y paz positiva, propone una reconceptualización de esta justicia para el logro de una paz positiva, la cual se entiende como ausencia de violencia estructural o violencia económica, que es la que afecta el núcleo de los derechos económicos y sociales.

Schmid y Nolan (2014: 17), teniendo en cuenta el principio de indivisibilidad e interrelación de los derechos humanos en el contexto transicional, también advierten sobre una debida conceptualización de los derechos económicos y sociales, y sostienen que un apropiado uso del lenguaje permitirá una adecuada delimitación de las obligaciones que impone la protección de esta tipología de derechos.

Por su parte, Carranza (2008: 314) se concentra en el tratamiento de los delitos económicos, reparando especialmente en la corrupción, para advertir que es desacertado restar importancia o entender este tipo de conductas aisladas de lo que comporta la violación de los derechos humanos, dado que ese entendimiento no se compadece con las realidades que reflejan los países en desarrollo. En ese sentido, el autor concluye que las luchas contra la pobreza y la desigualdad también deben ser incorporadas como objetivos estratégicos de la justicia transicional.

Esta serie de argumentos construidos en el desarrollo del campo de la justicia transicional han ampliado el panorama de protección de los derechos humanos, que deben observarse en los contextos transicionales. Cabe apreciar de ese modo que en los procesos de construcción de paz sean cada vez más evidentes los esfuerzos para que en las sociedades se experimenten cambios que conduzcan al establecimiento de paz con características de estable y duradera.

Por ello, resulta indispensable entender la justicia transicional como protección de los derechos humanos sin clasificaciones que entorpezcan su concreción en la realidad. Este entendimiento conjunto permite el diseño de medidas que atiendan su protección integral, de acuerdo con cada contexto, donde se pretende dar la transición para superar momentos en los cuales la violencia ha alcanzado niveles que amenazan el orden social.

En otras palabras, no puede perseguirse la paz sin una lectura que abarque la incorporación de todos los derechos humanos, dejando atrás la división entre derechos civiles y políticos, y derechos económicos, sociales y culturales, la cual se contrapone a la realidad que experimentan las sociedades que le apuestan a la transición. 


\section{La irenología como disciplina en diálogo con la justicia transicional}

Como se mencionó al inicio del documento, la Primera y la Segunda Guerra Mundial fueron sucesos determinantes para el desarrollo de campos como el de la justicia transicional y son íconos de las atrocidades que han flagelado a la humanidad. El impacto que ocasionó tanta crueldad dio paso a la concreción de diversas acciones encaminadas a prevenir que sucesos como esos se repitieran.

En medio de esa variedad de respuestas, cada vez tuvieron mayor importancia los estudios profundos de los fenómenos de la guerra y la paz, y con ello, el surgimiento de nuevas disciplinas. Así, en el caso de la guerra, la polemología se encargó de su análisis, bajo el adagio romano: "Si quieres la paz conoce la guerra”, retomado por el exponente de la polemología Gastón Bouthoul (1984: 58), quien consideraba que para poder curar a la humanidad de la guerra - a la cual veía como un fenómeno social susceptible de ser estudiado- esta debía ser conocida a profundidad.

Aunque sus estudios estuvieron rodeados de fuertes críticas por tener como unidad de análisis la guerra y no la paz, cabe considerarlos como una contribución al campo de la investigación para la paz, por haberse fijado como hipótesis el logro de esta a través del estudio de la guerra.

La otra disciplina que surgió para avanzar en la construcción de sociedades pacíficas y cuyos postulados sustentan este documento fue la irenología, la cual:

Es definida por Starke como un cuerpo de teorías, conceptos, hipótesis, principios generalizadores, leyes generales, deducciones y proposiciones formuladas sobre el tema de la paz, dirigidos a identificar fuerzas y condiciones que, desde una perspectiva positiva, ayudan al mantenimiento de un régimen pacífico en tanto que, a partir de la óptica negativa, pueden ser quebrantadores del mismo. Asimismo, incluye el análisis sistemático de los procedimientos y métodos formales necesarios para asegurar la paz (Cabello-Tijerina, 2015: 122).

En ese sentido, la justicia transicional como modelo para transitar hacia la paz, y conforme se viene esbozando, es una unidad de análisis que se encuentra bajo el abrigo de la irenología.

Si bien los estudios de paz se fueron desarrollando de la mano con las investigaciones sobre el fenómeno de la violencia, dieron un giro importante cuando esos análisis empezaron a desplazarse hacia una tipología de violencia que ya no solo incluyera esa violencia directa - física o psicológica- y que fue la que ocupó el interés de los investigadores por mucho tiempo, sino que se incorporó la violencia estructural y la violencia cultural como 
nuevas propuestas construidas por Johan Galtung, que, como lo indica Jiménez (2009: 2), reactivaron el campo de la investigación para la paz, el cual, además, es considerado hoy por hoy como "una ciencia social aplicada y explícitamente orientada en valores” (Jiménez y Jiménez, 2014: 150).

Galtung (1969: 183) se plantea una problemática respecto de los estudios de paz cuando halla que la violencia está siendo entendida de una manera restringida, lo cual ha llevado a que las miradas estén siempre enfiladas, casi que estrictamente, a la violencia directa. Justo por ello propone una extensión del concepto de violencia, lo cual, afirma, conduce a un concepto ampliado de paz.

En esa dirección, este autor enfatiza en una tipología de la violencia, identificando tres tipos: violencia directa, violencia estructural y violencia cultural. Esta triangulación que hace sobre el comentado fenómeno le permite formular otra similar figura sobre la paz. En efecto, se proporcionan sendos conceptos de paz: directa, estructural y cultural.

No obstante ser precisamente la amplificación de la concepción de violencia la que permite dimensionar mejor el concepto de paz y, por tanto, diseñar las estrategias que acercan a su construcción de acuerdo con sus diferentes clasificaciones, este artículo fija su atención, sin menoscabar los demás conceptos, en la violencia estructural en yuxtaposición a la paz estructural, entendida esta última dentro de los contornos de la justicia so$\mathrm{cial}^{3}$, y que es el deber ser al cual se le apuesta desde la óptica de los derechos económicos y sociales, que son los mismos que han estado al margen de los procesos transicionales, tal cual se explicitó en el anterior apartado.

Y en razón a que tanto la justicia transicional como la irenología tienen como hipótesis la construcción de sociedades pacíficas, se evidencia que confluyen en detectar la necesidad de incluir en sus análisis a la justicia social. Esta afirmación cobra sentido cuando se observa que desde la justicia transicional se promueve la incorporación del respeto y garantía a los DESC en las transiciones, y desde la irenología la proposición del concepto de paz estructural.

Para Galtung (2003: 11), la violencia estructural está dada por la explotación como pieza central dentro del contexto de la estructura de una sociedad y se percibe como una división existente dentro de determinada sociedad

3 Murillo y Hernández (2011: 12) identifican tres grandes vertientes de la justicia social: aquella que se enfoca en la distribución de bienes, recursos materiales y culturales, capacidades; otra que se centra en el reconocimiento y respeto cultural de todas y cada una de las personas y en la existencia de relaciones justas dentro de la sociedad; y finalmente, la participación en decisiones que afectan la vida en sociedad. 
entre los que están en una posición superior y obtienen mayor provecho de la estructura, y quienes están en una posición inferior. A causa de esto, quienes se encuentran en posiciones inferiores pueden morir de hambre o desgastados por enfermedades o quedar en un estado permanente de miseria, que incluye malnutrición y padecimiento de enfermedades. Justo como sucede en la tradicional división de ricos y pobres, y que es percibida por algunas de las mujeres entrevistadas como una causa del conflicto en Colombia:

La desigualdad. Sí, porque como los ricos siempre tienen más y los derechos de los pobres pues siempre son más vulnerables (E11).

Para reforzar esa estructura de explotación, se combinan varias acciones que este autor denomina: penetración -implantación de los dominantes en el interior de las personas dominadas-; segmentación — proporcionar a la parte inferior una visión muy parcial de la realidad—; marginación — dejar por fuera a la parte inferior-y fragmentación - mantener a las personas de la parte inferior separadas entre sí-.

Estas acciones así entendidas se perciben en la realidad como una injusta distribución de la riqueza y en la falta de oportunidades que hunden cada vez más a las sociedades en la pobreza y que intensifican unos contextos que resultan propicios para que se reproduzca cada vez más el triángulo de la violencia - directa, estructural y cultural-.

En esas circunstancias son determinantes las acciones encaminadas hacia el papel de la protección de los derechos económicos y sociales, cuya dirección, según Zuleta (2009: 5), es la de garantizar a los individuos las condiciones y niveles básicos de bienestar que se traducen esencialmente "en alimentación, seguridad social, salud física y mental, vivienda, trabajo, sindicalización, educación, medio ambiente sano y agua".

Estos apuntes permiten dar suficiente comprensión a varias situaciones que en la realidad están sufriendo interpretaciones aisladas o descontextualizadas, resultando, verbigracia, tan injusta la muerte que se ocasiona a mano armada como aquella producida por el hambre; aunque a menudo, visiblemente, impacta más el primer supuesto (véase Gráfica 2). Por ello, la justicia transicional, hoy por hoy y de acuerdo con sus avances, debe ser vista como un campo, cual lo analiza Greiff (2011: 18), donde se concentren y destinen los esfuerzos a brindar diferentes mecanismos para que las sociedades que han soportado los horrores de la guerra transiten hacia la paz; pero también, hay que añadirlo, debe ser una disciplina que impulse la protección de todos los derechos humanos sin distinción alguna y que además esté a tono con el desarrollo que desde la irenología han alcanzado los estudios para la paz. 
Con estos prolegómenos, conviene ahora aplicarse al análisis de la paz que se busca alcanzar en el Acuerdo de Paz celebrado entre el gobierno colombiano y las FARC.

\section{La importancia de la paz territorial en Colombia desde una perspectiva femenina}

Al referirse al enfoque territorial, el Acuerdo de Paz explicita que este:

Supone reconocer y tener en cuenta las necesidades, características y particularidades económicas, culturales y sociales de los territorios y las comunidades, garantizando la sostenibilidad socio-ambiental; y procurar implementar las diferentes medidas de manera integral y coordinada, con la participación activa de la ciudadanía (Gobierno Nacional y FARC, 2016: 6).

Por ello, es trascendental aplicarse a comprender cómo se concibe la paz en la mente de los ciudadanos - las mujeres concretamente según la delimitación de este trabajo-, pues esta visión territorial impone el reto del reconocimiento y respeto por la diferencia, en virtud de las características sociales, económicas y culturales diversas que afronta cada región. También apremia a identificar las zonas donde el conflicto ha causado más estragos y donde precisamente se halla la población más vulnerable. Zonas en las que para crear criterios de priorización que atiendan a esos contextos más críticos se requiere no solo que el Estado haga "presencia" -misma que por mucho tiempo ha dejado de hacer-, sino que redoble sus empeños para reconstruir cada uno de los aspectos de la vida social que fueron desconocidos en tiempos de conflicto.

Al final de cuentas, la idea de paz debe suponer, y a eso apunta el Acuerdo, implementar novedosas políticas encaminadas a la solución de esas injusticias sociales, que en buena parte fueron el caldo de cultivo para la conformación de grupos al margen de la ley.

Esta labor, sin duda, debía incluir como lo hace la garantía de los derechos económicos y sociales, como la vivienda, la alimentación, la educación, la seguridad social, la salud física y mental, el goce de un medio ambiente sano y el suministro de agua, por ser justamente esa falta de disfrute lo que ha puesto a gran parte de la población en situación de vulnerabilidad y que son factores que suman a las causas profundas y estructurales del conflicto.

En ese sentido, el enfoque territorial de la paz que se encuentra contenido de manera transversal en el Acuerdo de Paz colombiano responde a las preocupaciones de la inclusión de los derechos económicos, sociales y culturales, que han sido desplazados y relegados en la agenda del campo de la 
justicia transicional, y que son indispensables para cerrar la brecha entre ricos y pobres al aminorar también esas iniquidades entre lo rural y lo urbano, intención que se evidencia en el preámbulo del mismo (Gobierno Nacional y FARC, 2016: 2), además de encontrarse a la vanguardia del desarrollo que desde la irenología se ha dado en los temas de paz y puntualmente en lo que concierne con la paz estructural.

Por todo lo anterior, se puede afirmar que en el contexto colombiano se perciben hoy de manera más palpable los esfuerzos que se están haciendo para pasar la página del conflicto social. También se observa la voluntad política de los actores del conflicto para transitar exitosamente hacia la paz, valiéndose de la noción de paz territorial como estrategia que afronta las causas estructurales del conflicto e involucra y promueve la participación de las regiones en la definición de los temas sociales importantes que marcan el curso de su desarrollo.

Esto constituye un importante paso para la reconstrucción de una sociedad desintegrada y fragmentada a causa del conflicto, en la medida que esta dinámica lleva implícito un mensaje del compromiso que concierne a las regiones con la agenda de paz. En un intento por acotarlo, podría encerrarse en el lema "Pensar globalmente, actuar localmente", lo cual, además, no solo toca a los territorios sino a cada ciudadano individualmente considerado. Las mujeres entrevistadas también comprenden esto cuando indican que son principalmente los ciudadanos los encargados de la construcción de paz en el país (véase Gráfica 3).

Al ser esa construcción de paz un proceso que involucra a toda la sociedad en su conjunto y que está lejos de ser un estado ideal de convivencia, en el cual sea el Estado encabezado por sus gobernantes el único llamado a garantizarlo, es necesario conocer cuáles son los potenciales aportes y cuáles los obstáculos que, en su cotidianidad, las mujeres con condiciones socioeconómicas desfavorables experimentan en relación con el tema de la paz.

$\mathrm{Al}$ respecto, las entrevistadas manifestaron con predominancia (véase Gráfica 4) que actualmente sus aportes para construir la paz en el país consistían en conservar unas adecuadas relaciones interpersonales, reconociendo también que era mínimo lo que podían aportar:

Pues yo no puedo decir que hago mucho, pero pues en mis manos casi no está nada como para yo decir yo ayudé en esto... Evitar los problemas, no me gustan los problemas, evitar los problemas, porque pues si uno se pone a pelear entonces hay más problemas y más problemas (E9).

Frente a ello, igual dijeron que podrían asumir un rol más importante en los procesos de construcción de paz, si se valorara más su opinión y fueran escuchadas: 
Pues que le dieran más importancia ¿no?, a la opinión de la mujer, que la dejaran participar más a la mujer, y pues no sé, escuchar más los pensamientos de las mujeres, que participemos más (E2).

Asimismo, como se muestra en la Gráfica 5, la igualdad de género, la unidad, el empleo y la participación en política, son determinantes para ellas a la hora de verse involucradas en los temas de construcción de paz, señalando que sus potenciales aportes se situarían en el campo del trabajo social, desde donde quisieran desarrollar actividades que contribuyeran a lograr el desarrollo dentro de sus comunidades, a través de programas adecuados que permitieran superar las principales problemáticas que se presentan al interior de ellas.

En este orden de ideas, resulta ser tan importante lo que el Estado, con toda su estructura, puede brindar para pasar la página del conflicto, como lo que cada persona está dispuesta a entregar de acuerdo con sus capacidades y disponibilidades. Adams se refirió a ello citando a Margaret Mead (Adams, 2014: 241) cuando evocó: "Nunca dudes de que un pequeño grupo de ciudadanos reflexivos y comprometidos pueden cambiar el mundo. De hecho, es lo único que siempre sucede".

De tal manera, la realización de la paz -seguramente uno de los más claros objetivos que comparte la humanidad- se desplaza de la hegemonía del Estado a la cotidianidad de los ciudadanos. Con ello, la paz empieza a repensarse como un proceso menos complejo, en el cual cada persona puede jugar un papel trascendente para hacer posible el tránsito hacia sociedades más pacíficas. En otras palabras, la paz está dejando de ser asunto exclusivo de los Estados para convertirse en uno que involucra activamente a los ciudadanos.

\section{Conclusiones}

Analizar la justicia transicional desde su origen permite comprender cuáles son los avances más importantes que ha logrado este campo, si se quiere como modelo, al cual se le reviste de idoneidad para transitar de un estado de guerra a uno de paz. Este puntual objetivo soporta en gran medida los cuestionamientos a los que se han sometido los procesos transicionales, verbigracia, ¿por qué después de la transición aún no se alcanza la paz?

En ese transcurrir, fue determinante acercarse a su estudio con una perspectiva lo suficientemente fuerte para hacer visible la relación entre la justicia transicional y los derechos humanos. Podría decirse que este paso marcó el antes y el después de los sistemas transicionales, preocupados en un inicio por el ejercicio del ius puniendi, que favorecía una visión limitada y hasta 
intangible de la paz, pues fijaba su atención solo en una protección privilegiada de los derechos civiles y políticos en desmedro de los asuntos involucrados con los derechos económicos, sociales y culturales.

Esto suponía que las violaciones cometidas contra los núcleos de este último grupo de derechos se tornaran invisibles, pese a que no con menos o poca importancia afectan la vida de las mujeres que conformaron este estudio y se convierten en situaciones que impiden la construcción de la paz.

Sumadas a esos alcances, y en un momento donde cada vez es más evidente la necesidad de la transdisciplinariedad para el avance de la ciencia, las investigaciones irenológicas se constituyen en grandes aliadas de las transicionales, porque introducen un paradigma amplio de la paz que se ha venido construyendo de manera paralela al de la violencia y que ha permitido identificar una tipología de paz, procurando así el análisis profundo de las causas que la imposibilitan y la manera más conveniente de gestionarlas. En efecto, la irenología correlacionada con la justicia transicional puede verse como la ciencia que estudia la finalidad de esta última: la paz. Esta es entonces la razón más poderosa para descubrir la sinergia entre una y otra.

Es así como los avances logrados por la justicia transicional y la irenología han permitido que las preocupaciones y cuestionamientos sobre los temas de paz estén hoy en día repensándose hacia perspectivas más amplias en las que si bien los crímenes más atroces que han amenazado y violentado la vida, la libertad, la paz y la seguridad no dejan de ser un asunto de especial trascendencia en un Estado de derecho, también comienzan a serlo las cuestiones estructurales, sociales y económicas que se mantienen en las raíces de los macroconflictos sociales y que vulneran otros derechos no menos importantes como los económicos, sociales y culturales, a los cuales se protege desde una visión integral de respeto de los derechos humanos, atendiendo al principio de indivisibilidad que los inspira.

Las nuevas perspectivas que abren estos campos también han ayudado a superar la discusión histórica que ha tenido lugar desde la Guerra Fría en cuanto a qué tipo de derechos humanos se debe privilegiar, esto es, si merecen un mayor grado de protección los derechos civiles y políticos que los derechos económicos, sociales y culturales, o viceversa, pues en este tercer milenio ya no caben semejantes discusiones abiertamente alejadas de las actuales problemáticas sociales, tal como pudo observarse desde la perspectiva de las mujeres.

Las acepciones más amplias creadas sobre la paz -como una de las contribuciones más importantes que aporta la irenología- permiten determinar desde qué ángulo se debe abordar el conflicto que la amenaza y 
han contribuido a que se reflexione de forma contextualizada sobre la mejor manera de construirla, superando también la práctica de importar modelos que no atienden a las precisas circunstancias que se pretenden conjurar.

Asimismo, se empieza a hacer con mayor rigor la apuesta para que los asuntos que posibilitan el mantenimiento y la construcción de paz sean no solo procesos más cotidianos, sino también más palpables para los ciudadanos, en especial para la población marginada. Esto invita a redoblar esfuerzos de manera que surja en los ciudadanos la necesidad de involucrarse activamente en estas temáticas de la vida social y su día a día se encuentre constantemente motivado por la preocupación acerca de cuáles son las cuestiones que, desde su órbita personal, pueden transformar para contribuir a que la sociedad a la cual pertenecen sea una sociedad pacífica.

En conclusión, un paradigma de justicia transicional irenológica, donde se aglutina un sistema de paz con una ciencia de la paz, responde a las tendencias que marcan el desarrollo de estos campos, pero también a las necesidades reales, las cuales emergen de las experiencias de las sociedades que asumen una transición. Por eso permite trabajar de modo más cercano y tangible al establecimiento de una paz estable y duradera. En esa vía se encuentra el concepto de paz territorial que acoge el Acuerdo de Paz para Colombia.

\section{Referencias}

Adams, David (2014), Cultura de Paz: una utopia posible, México: Herder.

Arbour, Louise (2006), "Economic and social justice for societies in transition", en Center for Human Rights and Global Justice, núm. 10, Estados Unidos: New York University School of Law.

Barbosa, Francisco (2017), ¿Justicia transicional o impunidad?, Colombia: Ediciones B.

Bouthoul, Gaston (1984), Tratado de polemologia, España: Ediciones Ejército.

Boven, Theo van (1993), "Estudio relativo al derecho de restitución, indemnización y rehabilitación a las víctimas de violaciones flagrantes de los derechos humanos y las libertades fundamentales". Disponible en: http://www.un.org/en/ga/search/view_ doc.asp?symbol=E/CN.4/Sub.2/1993/8\&Lang=S [6 de febrero de 2019].

Cabello-Tijerina, Paris (2015), "La irenología como pilar de la ciencia de la mediación", en Gorjón, Francisco et al. [comps.], La ciencia de la mediación, México: Tirant Lo Blanch.

Carranza, Ruben (2008), "Plunder and pain: should transitional justice engage with corruption and economic crimes?", en The International Journal of Transitional Justice, vol. 2, Inglaterra: Oxford University Press.

Chaparro, Nina y Martínez, Margarita (2016), Negociando desde los márgenes: la participación politica de las mujeres en los procesos de paz en Colombia (1982-2016), Colombia: Dejusticia. 
Convergencia Revista de Ciencias Sociales, núm. 80, 2019, Universidad Autónoma del Estado de México

Comisión Colombiana de Juristas (2007), Principios internacionales sobre impunidad y reparaciones, Colombia: Opciones Gráficas Editores.

Jiménez, Francisco (2009), "Hacia un paradigma pacífico: la paz neutra”, en Convergencia. Revista de Ciencias Sociales, vol. 16, México: Universidad Autónoma del Estado de México.

Jiménez, Francisco y Jiménez, Francisco (2014), “Una historia de la investigación para la paz”, en Historia Actual Online, núm. 34, España: Universidad de Granada, Instituto de la Paz y los Conflictos.

Galtung, Johan (1969), "Violence, peace, and peace research", en Journal of Peace Research, vol. 6, núm. 3, Noruega: International Peace Research Institute.

Galtung, Johan (2003), “Violencia cultural”, en Gernika Gogoratuz, núm. 14, España: Gernika Gogoratuz.

Gobierno Nacional y FARC (2016), "Todo lo que necesitas saber sobre el acuerdo de paz”, en Oficina del Alto Comisionado para la Paz de Colombia. Disponible en: http://www. altocomisionadoparalapaz.gov.co/herramientas/Documents/Acuerdo-Final-AF-web. pdf [29 de octubre de 2017].

Greiff, Pablo (2011), “Anuario de Derechos Humanos Universidad de Chile”. Disponible en: http://www.anuariocdh.uchile.cl/index.php/ADH/article/view/16994/18542 [20 de marzo de 2017].

Murillo, Javier y Hernández, Reyes (2011), "Hacia un contexto de justicia social”, en Revista Iberoamericana sobre Calidad, Eficacia y Cambio en Educación, vol. 9, núm. 4, España: Red Iberoamericana de Investigación sobre Cambio y Eficacia Escolar.

ONU (1993), "Declaración y Programa de Acción de Viena”. Disponible en: http://www. un.org/en/ga/search/view_doc.asp?symbol=A/CONF.157/23\&Lang=S $[5$ de febrero de 2019].

ONU (2014), Justicia transicional y derechos económicos, sociales y culturales, Estados Unidos y Suiza: Naciones Unidas.

ONU (2004), "El Estado de Derecho y la Justicia de Transición en las sociedades que sufren o han sufrido conflictos", en Naciones Unidas Consejo de Seguridad, núm. 616, Estados Unidos: ONU.

Régimen Servicios Públicos Domiciliarios (1994), “artículo 102”, en Ley 142. Disponible en: http://www.alcaldiabogota.gov.co/sisjur/normas/Normal.jsp?i=2752 [22 de abril de 2018].

Schmid, Evelyne y Nolan, Aoife (2014), “Do no harm'? Exploring the scope of economic and social rights in transitional justice", en The International Journal of Transitional Justice, vol. 8, Inglaterra: Oxford University Press.

Sharp, Dustin (2012), "Adressing Economic Violence in times of transition: Toward a positive-peace paradigm for transitional justice", Fordham International Law Journal, vol. 35, núm. 3, Estados Unidos: Berkeley Electronic Press.

Teitel, Ruti (2003), "Genealogía de la justicia transicional”, en Harvad Human Rights Journal, vol. 16, Estados Unidos: Spring.

Zuleta, Nicolás (2009), "Presentación”, en González, Pablo [comp.], Derechos económicos sociales y culturales, Bogotá: Universidad libre de Colombia. 


\section{Anexo}

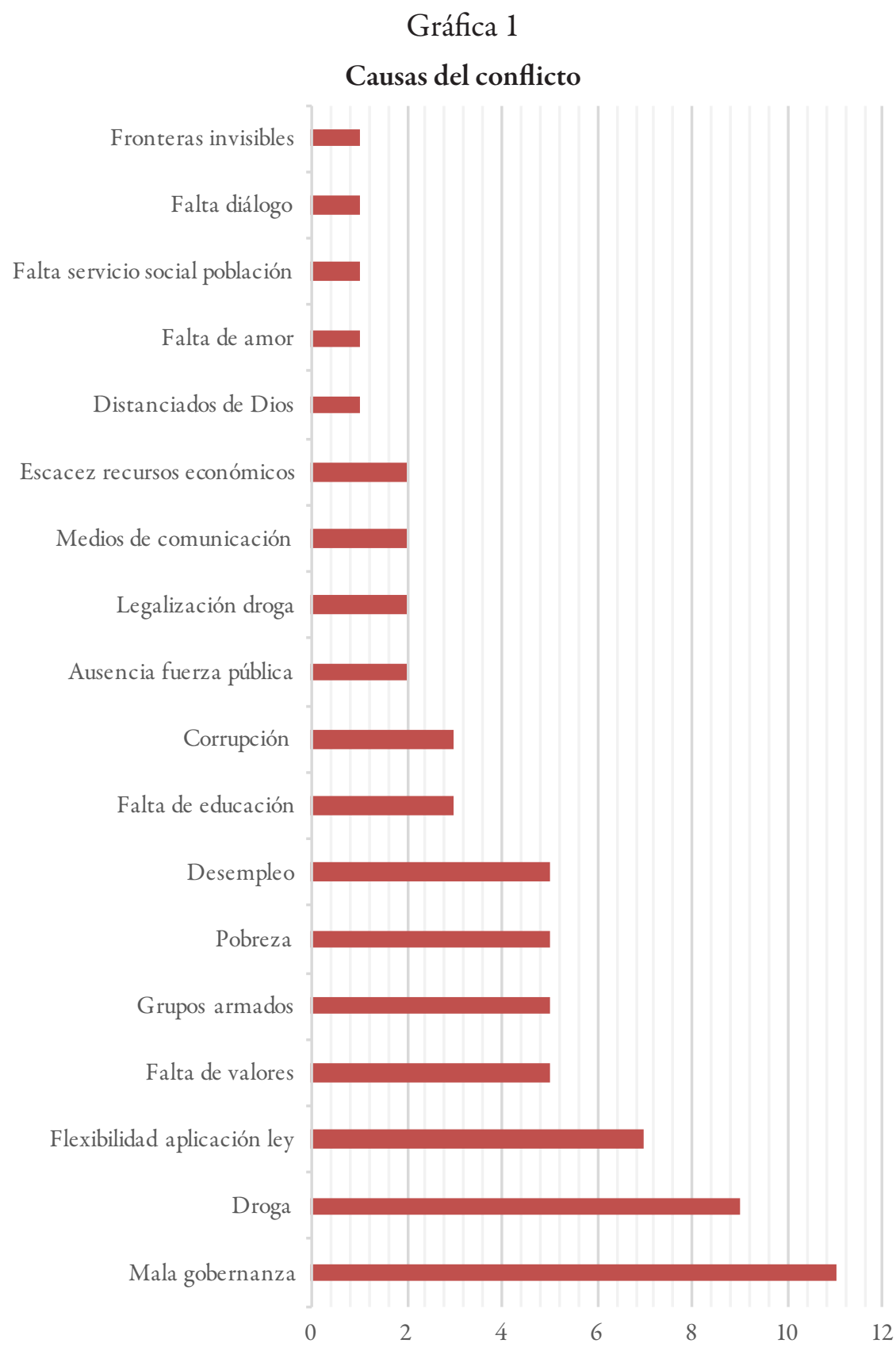

Fuente: Elaboración propia. 


\section{Gráfica 2}

\section{Consecuencias del conflicto}

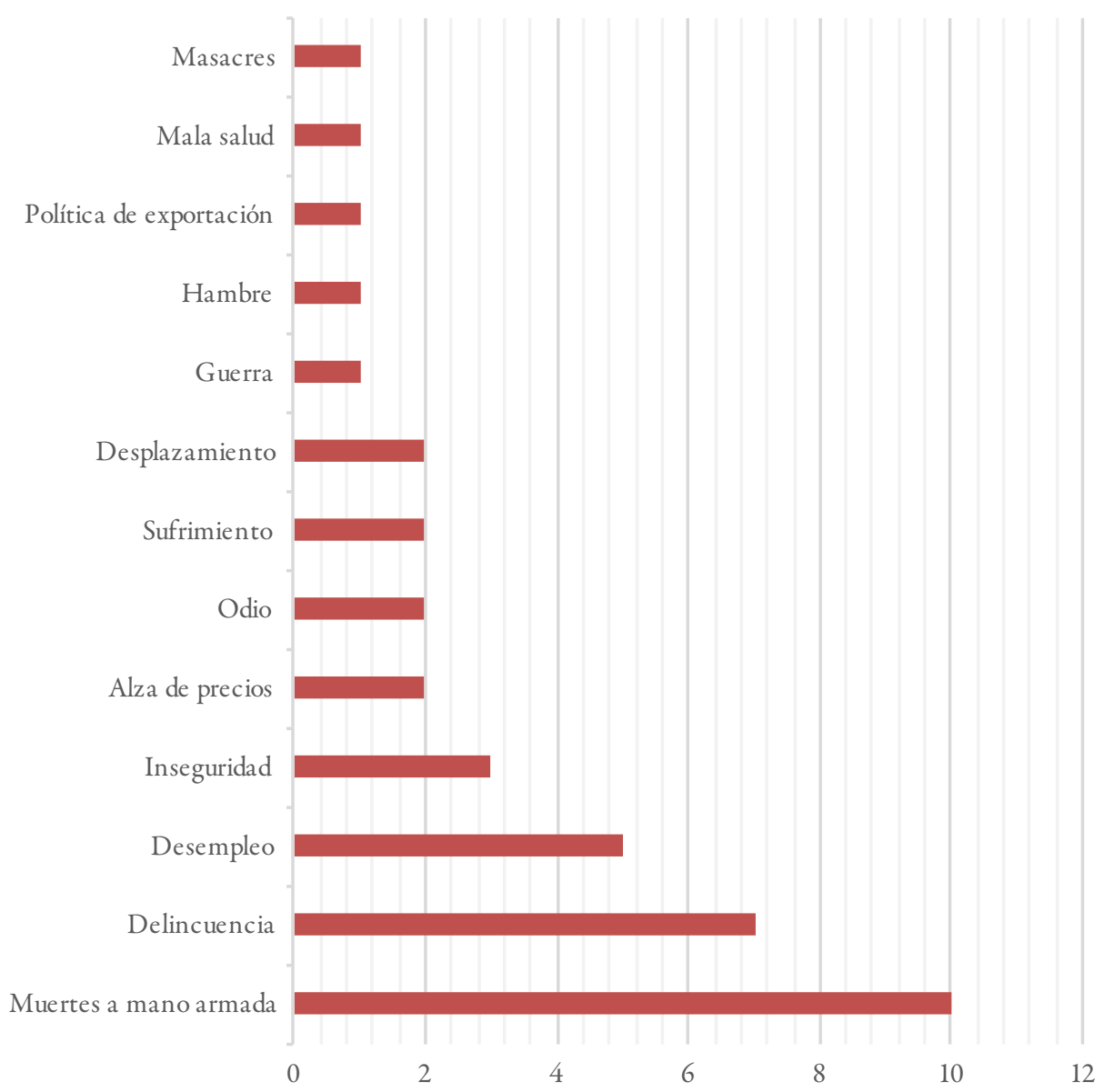

Fuente: Elaboración propia. 


\section{Gráfica 3}

\section{Encargados de la paz}

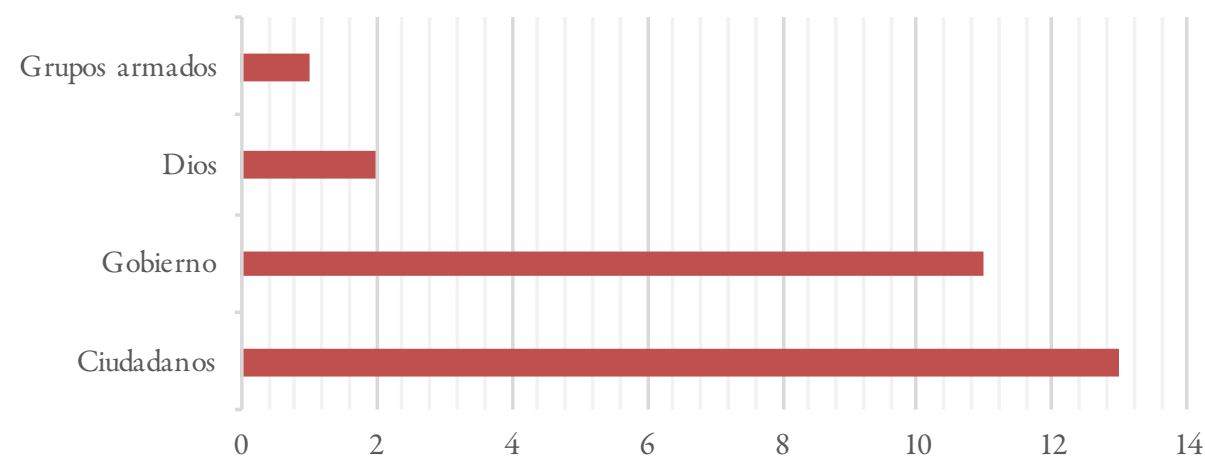

Fuente: Elaboración propia. 


\section{Gráfica 4}

\section{Aportes cotidianos para la paz}

Cambio de actitudes con las personas

Ayuda a quien lo necesita

Adecuadas relaciones familiares

Comparte conocimientos religiosos

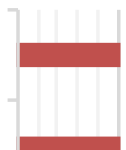

Pedirle a Dios

Buen desempeño en su trabajo

Buena crianza a los hijos

Buena consejera

No realiza aportes

Buenas relaciones interpersonales
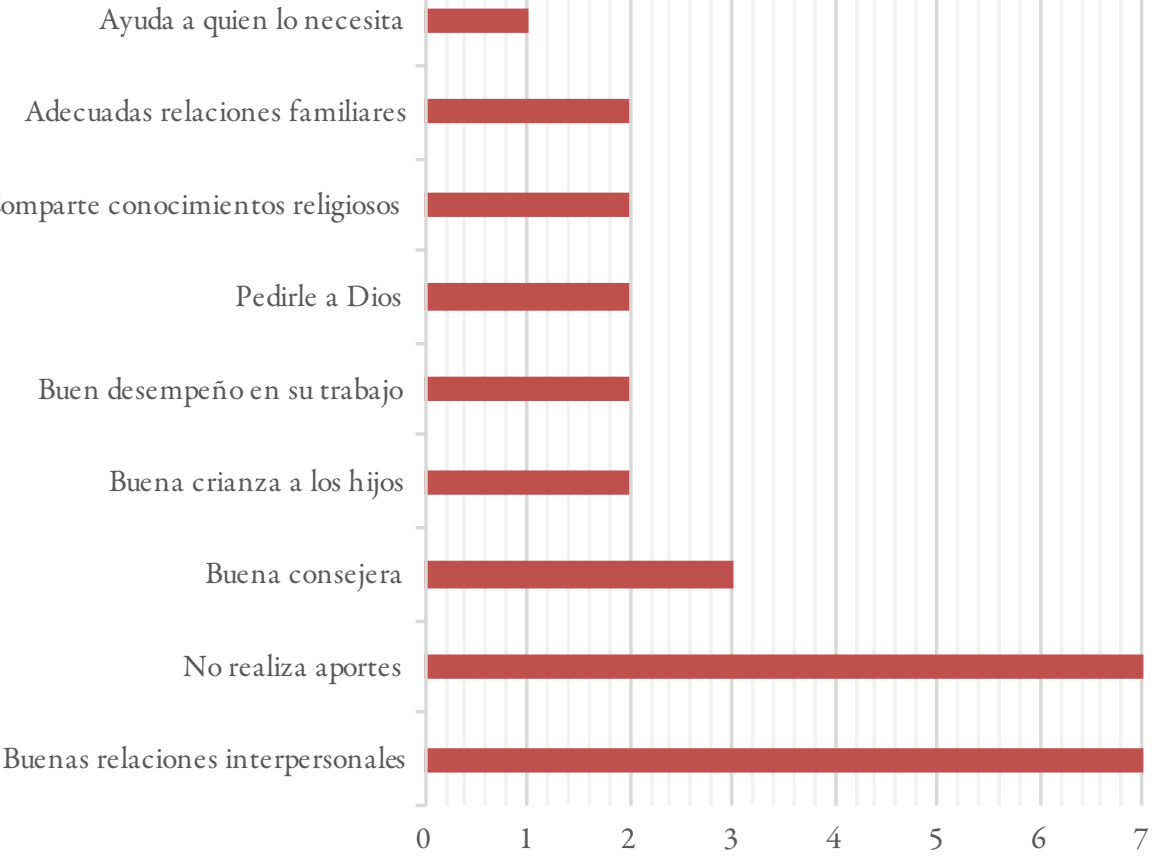

Fuente: Elaboración propia. 


\section{Gráfica 5}

\section{Condiciones para aportar a la paz}

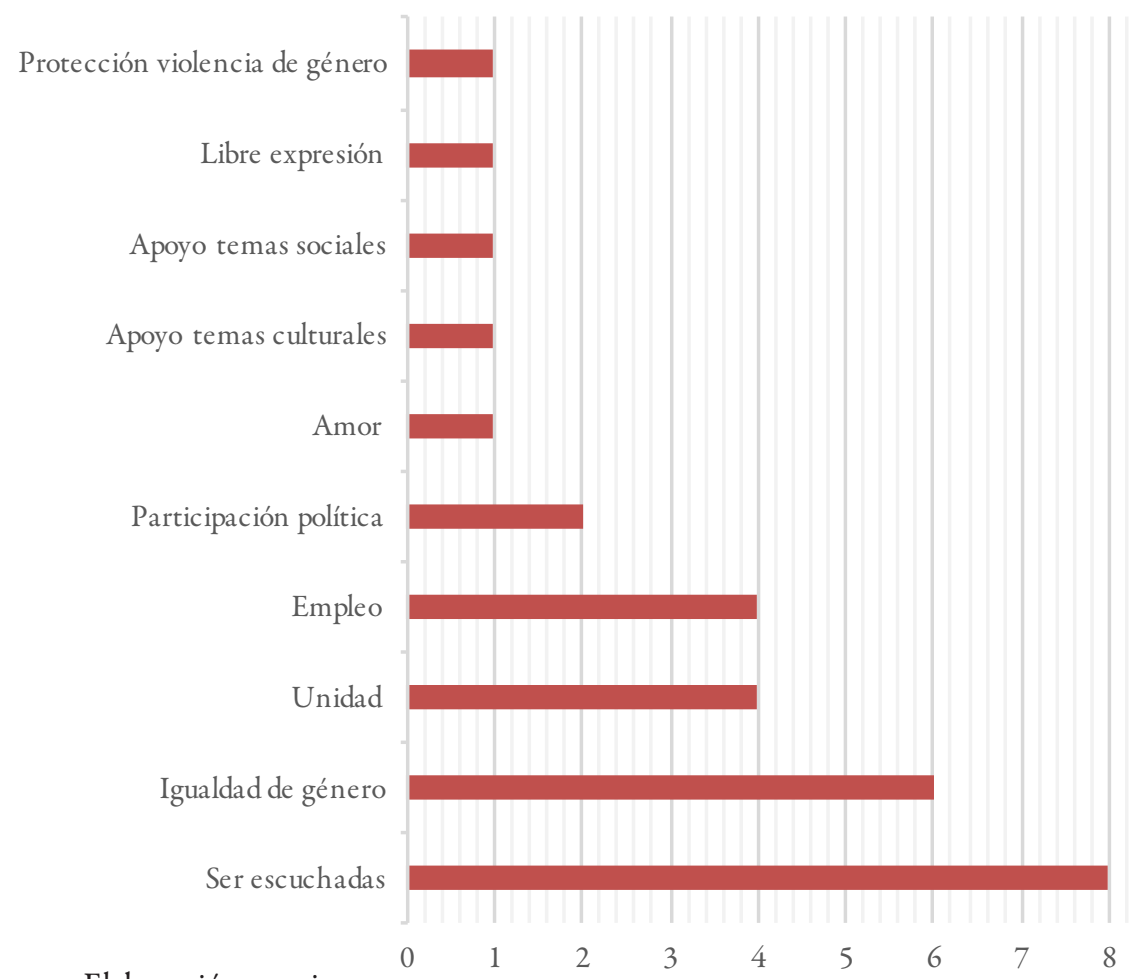

Fuente: Elaboración propia. 


\section{Gráfica 6}

\section{Potenciales aportes de la mujer en la paz}

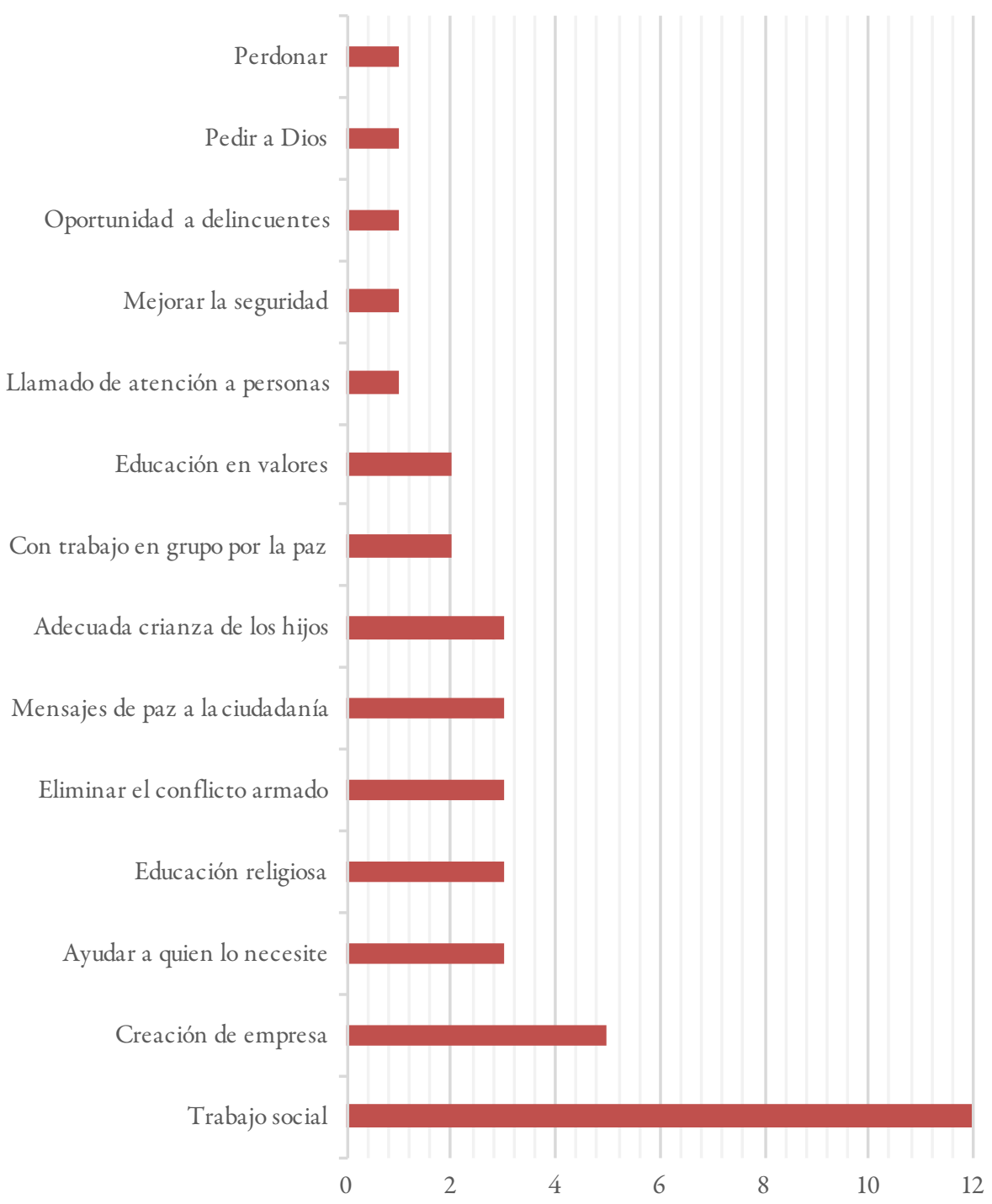

Fuente: Elaboración propia. 
Paris A. Cabello-Tijerina. Profesor-investigador de la Universidad Autónoma de Nuevo León; IDorcid.org/0000-0002-0191-2488. ResearchID. 0-19742017. Doctor en Intervención Social y Mediación por la Universidad de Murcia, investigador nivel I del Sistema Nacional de Investigadores, del Consejo Nacional de Ciencia y Tecnología, México. Profesor con reconocimiento Perfil PRODEP, miembro del cuerpo académico consolidado de Métodos Alternos de Solución de Conflictos de la UANL-CA-328. Catedrático en el Doctorado y en la Maestría en Métodos Alternos de Solución de Conflictos de la UANL; fundador de Estudios de Paz y Conflictos, investigador del Centro de Investigación de Tecnología Jurídica y Criminológica de la Universidad Autónoma de Nuevo León. Líneas de investigación: mediación como vía irenológica, polemología e irenología. Publicaciones recientes: Cabello-Tijerina, Paris Alejandro y Vázquez-Gutiérrez, Reyna Lizeth (2018) Cultura y Educación para la Paz. Una perspectiva transversal, México: Tirant lo Blanch, Cabello-Tijerina, Paris Alejandro et al. (2017), Cultura de Paz, México: Patria; Cabello-Tijerina, Paris Alejandro (2015), "La Irenología como pilar fundamental de la ciencia de la mediación”, en Gorjón, Francisco et al. [eds.], La ciencia de la mediación, México: Tirant lo Blanch; CabelloTijerina, Paris Alejandro [coord.] (2015), Diversas miradas un mismo sentir: Comunicación, Ciudadanía y Paz como retos del siglo XXI, México: Plaza y Valdés.

Karen Andrea Quiñones-Díaz. Becaria Conacyt e investigadora de la Universidad Autónoma de Nuevo León; doctoranda en Métodos Alternos de Solución de Conflictos de la misma universidad; IDorcid.org/00000002-7963-8175. Maestra en Derecho de la Universidad Santiago, de Cali, Colombia. Líneas de investigación: justicia transicional y métodos alternos de solución de conflictos. 